\title{
DETERMINISMO/POSITIVISMO VERSUS \\ INDETERMINISMO/NEOCONSTITUCIONALISMO: OBSERVAÇÕES SOBRE O TEMPO E O PROCESSO
}

\author{
Fernando Hoffmann ${ }^{1}$ \\ Larissa Nunes Cavalheiro ${ }^{2}$ \\ Valéria Ribas do Nascimento ${ }^{3}$
}

\section{RESUMO}

O presente artigo pretende discutir a relação entre Tempo e Direito, especialmente no que tange ao tempo processual. A discussão, centra-se na necessária (re)adequação do tempo no/do processo ao tempo social, tornando possível a tutela efetiva dos direitos albergados constitucionalmente. Para tal, crê-se necessária a re-inserção do processo - da jurisdição - no mundo-da-vida, eminentemente histórico e temporal, o que se dará por meio da hermenêutica filosófica.

Palavras-chave: Constituição. Hermenêutica. Processo. Tempo.

\section{INTRODUÇÃO}

São muitos os questionamentos sobre o "tempo", já á muito são várias as questões propostas. Desde Aristóteles e Platão, passando por Galileu e Copérnico, ainda Newton e o tempo idealizado, à ruptura temporal proposta pela relatividade de Einstein.

E em verdade, o que seria o "tempo" enquanto instituto - se assim pode ser denominado -, será ontem, hoje, amanhã? Será estático, ideal, móvel, constante ou inconstante? São estes questionamentos feitos desde a antiguidade - para uma maior delimitação do trabalho, será feita tal analise a partir das idéias de Newton - e, que, ainda hoje, não encontram respostas absolutas.

No entanto, não é escopo e, muito menos pretensão do autor dirimir tais dúvidas. A intenção aqui, é de maneira breve - mas não superficial - tratar deste animal indócil - o tempo - de forma a relacioná-lo com o Direito e, ademais com o modelo normativo positivista, bem como, (re)pensando a relação tempo/norma em época de neoconstitucionalismo(s) e subvertendo a lógica temporal-processual.

\section{PARA UMA BREVE HISTÓRIA JURÍDICO-TEMPORAL}

De pronto, fala-se do tempo estando em meio ao tempo, pois não se aborda sobre o mesmo, estando em uma condição ideal atemporal, em verdade sempre se esta na temporalidade. No entanto, em que espaço esta-se inserido? Em um instante que já é passado e, nem bem sendo presente já se transforma em futuro? 
Assim, tentar-se-á falar do nosso tempo, o "atual", tratando-o como um hoje sem que este seja presente, sendo apenas o momento temporal em que se esta inserido. ${ }^{4}$

Porém, mesmo com esta noção de estar-se no tempo, até a modernidade não se tinha a idéia de ação temporal, mas sim, de um tempo congelado e determinista. Newton dirá que o tempo - sua passagem - é uniforme, universal, absoluta, independendo assim do observador, e tendo o tempo como um conceito idealizado. ${ }^{5}$

Desta forma, em verdade, Newton faz coro com os racionalistas e suas idealizações - no direito, a segurança jurídica, a pacificação social, as verdades absolutas, a norma posta e ideal - tal qual o tempo newtoniano - o que importa a destemporalização - retirada do tempo enquanto instituto, do mundo - do tempo. Assim:

\begin{abstract}
Estamos defronte a um mundo sem novidades, pois tudo esta programado, uma vez que, conhecidas as condições iniciais, saberemos a condição futura, se é que podemos tratar de passado e futuro quando ambos têm o mesmo papel. Quer se dizer com isso que teríamos um universo estático, sem criação e previamente montado, onde a natureza e o homem em nada influenciariam, pois, se podemos saber o futuro conhecendo o presente, para esse se mostrar não pode sofrer perturbações. ${ }^{6}$
\end{abstract}

Newton tira o tempo do mundo - assim como os positivistas tiram do mundo, o Direito - e o coloca em uma outra dimensão ideal(izada), fazendo com que o tempo transcorra uniforme do passado ao futuro e, tornando-o reversível. "Newton inventou, portanto, um tempo escrupulosamente neutro, a sua mecânica reduz o passado e o futuro apenas ao momento presente" ${ }^{\prime 7}$. Mas onde fica a história, o mundo-do-ser Heidegger -, a ação do fluir temporal, ou seja, o tempo não é do mundo, e o mundo não esta no tempo - o que possibilita a estratificação das instituições políticojurídicas modernas.

Mas eis que surge Einstein e sua Teoria da Relatividade. Assim, passa o tempo a ser relativo a partir do observador. Einstein, afirma que tanto espaço quanto tempo são relativos e, que, em verdade o que é constante é a velocidade da luz. ${ }^{8}$ Deste modo:

\begin{abstract}
A Relatividade Especial é uma nova teoria da relação entre observadores. Ela subordina-se ao princípio pelo qual as leis físicas devem ser indiferentes ao modo particular de cada observador proceder à etiquetação dos fenômenos físicos segundo medidas de distância e duração. A conseqüência disso é devastadora: as medidas de distância (que definem o espaço) e de duração (que definem o tempo) não são mais absolutas. Seus valores deixam de ser os mesmos para todo observador, ou seja, cada observador recorta de um modo próprio, relativo ao seu "ponto de vista", a massa de acontecimento do mundo. $E$ esses recortes individuais, a espacialização e a temporalização que os observadores realizam sobre seus dados, são meras perspectivas irrelevantes para a descrição concreta desses acontecimentos. ${ }^{9}$
\end{abstract}

Logo, a partir de Einstein as verdades cientificas antes sólidas dissolvem-se no ar, os eventos não são mais determinados a priori, partindo-se de condições ideais 
que sempre produzirão os mesmos resultados finais. Assim, as ciências naturais são abarcadas pelo relativismo. No entanto, no Direito, tais modificações não se perpetuam - o que será aprofundado mais adiante.

Mas, este novo paradigma temporal, não condiz com a realidade da sociedade contemporânea. Assim, Prigogine lança seu olhar sobre o estudo dos Sistemas Dinâmicos e, apresenta-nos - mais profundamente - o caos, a complexidade, a instabilidade, trocando-se assim, as certezas da Física Clássica pelas probabilidades desta nova Física. ${ }^{10}$

\begin{abstract}
A ciência clássica privilegiava a ordem, a estabilidade, ao passo que em todos os níveis de observação reconhecemos agora o papel primordial das flutuações e da instabilidade. Associadas a essas noções, aparecem também as escolhas múltiplas e os horizontes de previsibilidade limitada. Noções como a de caos tornaram-se populares e invadem todos os campos da ciência, da cosmologia à economia. Mas como mostraremos neste livro, os sistemas dinâmicos instáveis levam também a uma extensão da dinâmica clássica e da física quântica e, a partir daí, a uma formulação nova das leis fundamentais da física. ${ }^{11}$
\end{abstract}

Quebra-se a simetria entre passado e futuro defendida pela física tradicional. 0 futuro não mais é previsível e, o passado, não pode mais ser reescrito, pois a partir da instabilidade são revistas as leis da natureza e, o tempo não mais começa ou termina, ele apenas transcorre e permeia todas as relações, sejam elas de origem científica, social, política, jurídica, etc. $O$ tempo existe e esta em nós. ${ }^{12}$

\footnotetext{
Chegamos assim a um tempo potencial, um tempo que esta sempre já aqui, em estado latente, que só exige um fenômeno de flutuação para se actualizar. Neste sentido, o tempo não nasceu com nosso universo: o tempo precede a existência, e poderá fazer nascer outros universos. ${ }^{13}$
}

Neste rumo, não só na ciência a incerteza se faz presente a partir da reconstrução paradigmática por qual passa o tempo - o qual importa mais precisamente neste trabalho. O espaço social também se torna complexo e instável, os acontecimentos sociais passam a ser imprevisíveis, no mundo globalizado os prognósticos cada vez mais se tornam inócuos.

O tempo da contemporaneidade não é mais o presente, mas sim o instante, não é mais o hoje, mas o agora. Mas se presente não o é, também não é futuro, pois o instante ao deixar de ser "tempo presente" torna-se futuro e, também em um mesmo instante já se torna passado. Assim, em meio á transmodernidade o tempo flui, o tempo é do mundo e por ele passa, tornando o por vir - sempre incerto - mais imprevisível ainda. Neste rumo:

O presente, sempre fugidio, constitui-se hoje como principal representação do tempo, símbolo de uma sociedade que perdeu sua crença na História. Como se o passado, definitivamente volvido, não tivesse mais nada para nos dizer, e o futuro, decididamente demasiado incerto, não pedisse para ser construído desde hoje. Sobretudo, como se o passado não pedisse para ser reinterpretado à luz das exigências do futuro, nem esse futuro enraizado 
na experiência do passado. Mergulhadas nessa brecha o presente, as nossas sociedades parecem órfãs da história, privadas de duração, voltadas unicamente ao fenesim do instante, condenadas a viver ao ritmo ofegante da actualidade. ${ }^{14}$

Então, face ás modificações paradigmático-temporais ocorridas nas ciências naturais desde a modernidade, qual é, ou, qual deveria ser o tempo do direito? Pois o Direito esta no tempo - é tempo - assim como tudo, ademais, é o Direito eminentemente temporal já que, inserido em determinada época e, tendo validade em determinado espaço, por determinado lapso temporal.

Pois, paradoxalmente, está a ciência jurídica imune às modificações ocorridas na esfera das ciências naturais, o Direito permanece aprisionado ao positivismo e, às concepções político-sociais da modernidade, sofrendo assim um deficti jurídicotemporal.

O positivismo coloca-se em si próprio para dizer o que é o Direito, pairando sobre tudo e todos como algo que esta fora do mundo e, que só encontra resposta para os conflitos em si. Assim, para a dogmática normativo-positivista, nada que seja Direito não é também, norma - norma esta que está posta contrafaticamente e atemporalmente. Assim:

[....] os positivistas convergem em tentar definir o direito com um sistema normativo autofundamentado, alheio à política e à moral. Todos eles definem o jurídico a partir do seu próprio interior, como, "norma válida" que tem em uma norma suprema seu objeto último. ${ }^{15}$

No entanto, mesmo o Direito positivo estando em si próprio, ele está no tempo, bem como, o tempo se faz presente no direito, entretanto, o tempo do jurídico deve adequar-se paradigmaticamente á dogmática clássica positivo-normativista. Desta forma, é no paradigma temporal newtoniano que o Direito moderno encontra morada - vislumbra-se claro já aqui que o tempo jurídico não acompanhou a evolução temporal científica. ${ }^{16}$ Pois as idealizações jurídico-sociais da modernidade - Estado Liberal - necessitam de uma temporalidade ideal(izada) que, assim como o direito positivo - positivado - seja dada atemporalmente, colocando-se assim, fora do mundo e fora do tempo mundano.

Nesta senda, tempo e Direito - que para o posivismo-normativista se reduz á norma - são postos ad eternun, pois não existem no "tempo", mas sim eternizados na norma posta do soberano/estado ou no tempo atemporal da ciência moderna - e, devidamente fechados às modificações da textura social. O Estado se modifica, as relações sociais tornam-se múltiplas e complexas, mas a norma está dada e, univocamente terá as soluções para os conflitos dos novos tempos.

Nesta maré, a temporalidade jurídica não condiz com a temporalidade pósmoderna, em tempos de globalização e, de crescente e constante reviravolta tecnológica, o jurídico tem de ser abarcado por esta complexidade da textura social. O social produz conflitos cada vez mais urgentes, vive-se o tempo da urgência, um tempo onde ontem, hoje e, amanhã se confundem e, onde os sujeitos jurídico- 
sociais não podem esperar as respostas de um Direito defasado temporalmente. ${ }^{17}$ Neste caminho:

\begin{abstract}
Na pós-modernidade, a sociedade passa a ter uma noção de tempo instantânea, uma noção de tempo rápida, uma noção de tempo manifestada pelos meios de comunicação, pela informática e pela internet, e os juristas continuam no texto escrito, no Código, na Constituição. Ou seja, há uma defasagem intensa entre a noção de tempo, a noção de sociedade na dogmática jurídica e o que é sociedade hoje. Assim, há um terrível paralelismo temporal, pois os juristas programam normas para durarem anos, e elas não duram, às vezes, dias. ${ }^{18}$
\end{abstract}

Assim, vislumbra-se claramente que, Direito, Tempo e Sociedade se interrelacionam já que, não existem tempo e direito fora do mundo da vida heideggeriano. Tempo, Direito e Sociedade são uma instituição mundana, onde ambos instituem-se e constroem-se simultaneamente, logo, o jurídico além de instituição político-social é também, instituição temporal. O direito nesse contexto deve ter um tempo próprio, instituinte do social, fazendo com que a defasagem tempo/direito/sociedade deixe de existir em ralação aos sujeitos jurídico-sociais. ${ }^{19}$

Contudo, esta defasagem jurídico-temporal, dá-se de forma mais contundente na atividade jurisdicional. A jurisdição como conhecemos hoje em terrae brasilis, ainda esta presa às instituições da modernidade jurídica. Logo, mesmo face á um novo cenário jurídico-social o magistrado ainda busca resposta preponderantemente na norma posta, via jurisdição racionalizada, atinente ao modelo estatal Liberal. Nesta linha:

\begin{abstract}
A jurisdição liberal foi afastada da política e conduzida a um isolamento das questões sociais importantes. Foi tomada como reprodutora da racionalidade legislativa, constituindo uma operacionalidade dogmática alienante, incapaz de pensar o conteúdo do direito, tornando-se fiel promotora da ordem política e econômica liberal. Sua tradição jurídica forjou uma instrumentalidade e uma teoria fechada em si mesma, suficientemente hermética para excluir do debate e da aplicação jurídicas qualquer matéria não contemplada previamente pelo ordenamento jurídico. Os limites políticos da jurisdição são também os limites da dogmática jurídica liberal que, para garantir a todo custo, a segurança jurídica, reduziu-se a uma burocracia simplista e orientou sua atuação para viabilizar os direitos e liberdades individuais contra a intervenção estatal. ${ }^{20}$
\end{abstract}

Ora, não pode a jurisdição nestes novos tempos de complexidade estar atrelada ao paradigma da racionalidade, assim, não só racionaliza-se o Direito que, surgirá apenas da norma, como também o tempo deste direito, que se manifestará racionalizado e imune às texturas temporais da pós-modernidade. Há que se romper com as amarras do paradigma moderno, matematizante da função jurisdicional, que faz do processo ainda hoje uma ciência natural.

O Direito Processual Civil ainda encontra-se compromissado com o paradigma racionalista que procurou fazer do Direito uma "ciência", sujeita aos princípios metodológicos utilizados pelas matemáticas. A redução do conceito de ciência, peculiar ao pensamento moderno, que somente 
concebe como científicos os ramos do conhecimento humano destinados a medir, pesar e contar, fez com que o Direito se transformasse num conjunto sistemático de conceitos, com pretensão à eternidade, desvinculando-o da História. ${ }^{21}$

A atividade jurisdicional nesta quadra da historia deve retemporalizar-se, ou seja, trabalhar com as novas condições temporais do mundo, pois, o Direito e, ademais o processo, "é necessário para fixar o que hoje - o que neste caso concretamente é o direito" ${ }^{22}$. Neste passo, na sociedade complexa e de risco em que se vive não cabe ao processo determinar apenas o direito que está posto, pois novos conflitos surgem a cada dia e, nem sempre, o novo está positivado normativamente. Desta forma, é que o processo uma vez que o direito encontra-se em constante mutação, está posto para "dizer" o direito inserido em determinada condição temporal, logo, na história. ${ }^{23}$ Deste modo:

[...] a lógica temporal da globalização é a do tempo real, ou seja, do tempo da simultaneidade; ao passo que o Direito criado pelo Estado normalmente difere o tempo, especialmente o tempo processual. A produção jurídica sempre olha para o passado para normatizar uma determinada conduta, projetando-a para o futuro. Já na perspectiva da globalização, pelo contrário, o tempo é o espaço da decisão atual. ${ }^{24}$

Resta evidente que tanto o Direito importa ao tempo, como o tempo importa ao direito e, que o processo é onde se manifesta a temporalidade jurídica. Porquanto, é neste diapasão que o processo não pode ser visto como mero procedimento lógico, qual fosse um rio que corre para o seu leito em total calmaria. O processo é sim, o lugar dos "distúrbios", uma seqüência de atos sim, mas não lógica e passiva, pois sim, conturbada e ilógica, que tem no seu tempo, o acontecer social, e por tal, deve, a sua temporalidade, estar relacionada com o mundo do ser. Assim:

Os fatos que interessam ao Direito Processual Penal ${ }^{25}$ ocorrem no tempo e
no espaço e são captados pela consciência humana e às vezes por
instrumentos. O espaço está diluído no tempo. A vida flui no tempo. O
mundo está no tempo. O homem só vê a matéria, mas o tempo precisa ser
constatado, porque decorre do movimento da matéria. O futuro não existe
ainda, nem existirá jamais, porque só existe o presente. O passado já não
mais existe e o presente representa um hiato entre estes dois tempos, e é
neste hiato que a vida flui, porque o tempo corre sempre. ${ }^{26}$

No entanto, qual será o tempo da nova jurisdição constitucional(izada)? Qual será o tempo do direito e ademais do processo face ao Estado Democrático de Direito? Será o tempo ideal(izado) da física newtoniana, ou, deverá estar o tempo da pós-modernidade envolto pelo caos, pela complexidade, pelo risco e, pela instabilidade da sociedade contemporânea? Para estas perguntas, é que, a partir de agora irá tecer-se algumas impressões, no entanto, sem a intenção de serem tais impressões, respostas - absolutas - a tais perguntas. 


\title{
20 TEMPO E A JURISDIÇÃO NA ERA DO NEOCONSTITUCIONALISMO
}

Assim, na esfera jurídico-política institui-se um novo paradigma jurídico-estatal, qual seja, o paradigma do Estado Democrático de Direito. De certo, nesta nova era deverá o Direito - e seus aplicadores - estarem preocupados com a manutenção e promoção dos textos constitucionais (re)nascidos do neo-constitucionalismo.

Logo, será no processo e, ademais, no modelo jurisdicional que deverão manifestar-se estas modificações político-jurídicas pós-modernas. Assim, espera-se o nascimento de uma jurisdição constitucional(izada) capaz de jurisdicionar as conflituosidades atinentes à sociedade de risco transmoderna. Bem como, capaz de concretizar e garantir os direitos emanados da constituição.

\begin{abstract}
Assim, está-se ante uma transformação suposta pela própria ordem constitucional pátria, considere-se, como aqui se supõe, que o ambiente da jurisdição não fica imune ao que marca a fórmula constitucional da democracia no Brasil (re)inaugurado em 1988. Ou seja: não se pode pensar a jurisdição como um espaço alheio às mudanças paradigmáticas do processo democrático. ${ }^{27}$
\end{abstract}

Para tanto, necessita-se de um novo processo (re)estruturado constitucionalmente e, (re)adequado a temporalidade transmoderna. Logo, um processo temporalmente social, em uma sociedade marcada pelo desassossego e pela instabilidade, como também, um processo constitucional, que dê amplitude ao texto positivado na Constituição. Donde a jurisdição não pode mais estar sujeita ao influxo temporal de um direito posto ad eternun, mas sim, deve fluir no curso do tempo e, ademais, da vida - estando inserido no mundo-da-vida heideggeriano.

\begin{abstract}
Em síntese, é a situação hermenêutica instaurada a partir do segundo pósguerra que proporciona o fortalecimento da jurisdição (constitucional), não somente pelo caráter hermenêutico que assume o direito, em uma fase póspositivista e de superação do paradigma representacional, mas também pela força normativa dos textos constitucionais e pela equação que se forma a partir da inércia na execução de políticas públicas e na deficiente regulamentação legislativa de direitos previstos nas Constituições.

É nisto que reside o que se pode denominar de deslocamento do pólo de tenção dos demais poderes em relação ao judiciário. Ora, tal circunstância implica um novo olhar sobre o papel do direito - leia-se constituição - no interior do Estado Democrático de Direito, que gera, para além dos tradicionais vínculos negativos (garantia contra a violação de direitos), obrigações positivas (direitos prestacionais). E isso, não pode ser ignorado, porque é exatamente o cerne do novo constitucionalismo. ${ }^{28}$
\end{abstract}

Neste passo, enquanto a modernidade era pesada, sólida, (in)coberta por certezas objetificantes e, caracterizada pela falta de movimento, é a pósmodernidade fluída, leve, envolta na subjetividade das incertezas e caracterizada pelo constante movimento de suas instituições, sejam estas jurídicas, políticas ou sociais. ${ }^{29}$ Logo, é o direito atingido por estas mudanças de rumo, sendo o processo o ramo jurídico mais afeito ás inquietações destes novos tempos. 


\begin{abstract}
Multiplicam-se assim, em quantidade e variedade, os fluxos de objetos técnicos que atravessam o corpo das sociedades atuais, induzindo a constituição de um inédito campo de mediação generalizada, em cujo centro está instalada a própria tecnologia. A principal conseqüência desse processo de tecnificação cada vez mais abrangente é pôr à prova a solidez dos sistemas tradicionais de valores, obrigando-os a passar por um regime de reajustes tão incessante quanto indeterminado. ${ }^{30}$
\end{abstract}

Neste caminho, as antigas instituições estão ruindo com a ação deste novo "tempo". O presente contemporâneo está vazio de significado, pois desassossegado pela desagregação social que atinge as comunidades contemporâneas. Assim, surge não mais do que como uma perspectiva de colapso o futuro, haja vista, o ser social não ter mais hoje sequer a garantia de seu agora. ${ }^{31}$ Desta forma:

\begin{abstract}
Dirigindo-se ao homem do século XIX, Nietzsche constatava: "...ainda tendes caos em vós, mas chegará um dia em que não mais o tereis". Somos esse dia: o dia da cientificidade do caos. Feliz o homem do século XIX, que podia viver o presente a expensas das utopias. No mundo atual o futuro foi todo gasto, já brota esgotado nas antecipações do presente, cobrando de nós seu débito em nossas dívidas, nossos vícios e nas doenças que portamos em nossos genes. ${ }^{32}$
\end{abstract}

Assim, face ás alterações do contexto social pós-moderno não pode o Direito e ademais o processo - seguir aprisionado pela temporalidade ficta moderna. Por certo, o direito processual precisa ser abarcado pela nova temporalidade científicosocial, passando a ser verdadeiramente dinâmico e, sobremodo, (re)adentrando ao mundo-da-vida, eminentemente temporal e histórico e por óbvio hermenêutico - aqui já se faz esboçada a importância da hermenêutica na retemporalização da atividade jurisdicional que, daí sim, passará a cumprir com o seu desiderato de efetivar e garantir direitos.

Deste modo, está o processo jogado no tempo, fluindo desordenadamente, embora, obedecendo determinada forma. Ademais, é o processo dinâmico, pois ao contrário do direito material, está calcado na incerteza e na possibilidade de ver ao fim do caminho materializado um direito. ${ }^{33}$

No entanto, neste caminho, mesmo partindo-se um estado inicial descrito a partir de condições ideais - se descrevêssemos o estado inicial de um sistema caótico precisamente - em certa altura do processo - do procedimento - tal condição inicial apenas indicaria um estado passado, mas, que, não necessariamente indicará um rumo certo na obtenção da resposta - da solução, da resolução deste determinado sistema. ${ }^{34}$ Sendo assim, deve-se romper com os grilhões da modernidade, abandonando-se a concepção liberal de jurisdição, bem como, a idéia matemática de obtenção da solução - decisão - adequada ao caso. Com efeito:

A jurisdição da modernidade, alheia à hermenêutica filosófica como modode-ser-no-mundo, tem apresentado diversos sentidos e significados que sofrem influência de um "procedimentalismo metodológico", do qual tem sido refém o poder judiciário, que "diz" o direito a partir de um lócus destemporalizado, preso a uma cultura (dogmática) metafísico-objetificante, 
que impede o seu desvelar como instância de realização dos direitos e garantias fundamentais. Aprisionada ao paradigma liberal-individualista típico do Estado Liberal, corroída pela filosofia da consciência que Ihe impõe permanecer num ambiente tradicional, a jurisdição não tem conseguido enfrentar os novos desafios e racionalidades instalado na sociedade contemporânea. Assim, a jurisdição, "procedimentalizada" "da" e "na" modernidade, apegada aos seus diversos "métodos de interpretação" tendo, pois, a hermenêutica como um "método", padece de uma espécie de "desontologização", ao resguardar uma "ordem" destemporalizada, impedindo que, nessa mesma ordem, possa haver interferências políticas ou valorativas que desafiam o pensamento tradicional, dando lugar às incertezas ao invés da certeza, aos riscos ao invés da segurança, e ao "caos" ao invés da racionalidade.

Neste talante, ao iniciar-se o rito processual na busca da resposta ao conflito indo ao encontro da decisão - a partir de uma condição ideal, não estaria assegurado ao jurisdicionado o encontro de uma decisão favorável, pois o processo, assim como os sistemas dinâmicos - caóticos - da nova física, está abarcado pelo indeterminismo e pela complexidade. Nesta maré:

A dinâmica do processo transforma a certeza própria do direito material na incerteza característica da atividade processual. Para Goldschmidt, "a incerteza é consubstancial às relações processuais, posto que a sentença judicial nunca se pode prever com segurança". A incerteza processual justifica-se na medida em que coexistem em iguais condições a possibilidade de o juiz proferir uma sentença justa ou injusta.

Não se pode supor o direito como existente (enfoque material), mas sim comprovar se o direito existe ou não no fim do processo. Justamente por isso é que se afirma que o processo é incerto, inseguro. ${ }^{36}$

Tal condição de incerteza é provocada por lidar o processo com fatos e estes fatos -, serem trazidos ao "rito" de forma conflitiva sendo reproduzidos parcialmente por partes que estão interessadas em determinado desfecho a partir desta reconstrução fático-temporal. Ainda, por óbvio, maior incerteza é trazida ao mundo processual por estarem os fatos - agora "processuais" - envoltos na complexidade da "vida", pois são fatos da vida, acontecidos a partir da conduta humana.

Assim, traz-se o Direito Processual para o mundo-do-ser, já que, enquanto lida com os fatos da vida, busca-se na tutela jurisdicional a compreensão destes fatos trazidos ao mundo do processo - que é o mundo-do-ser. No entanto, para que tal aconteça deve ser desvelado o "ser" processo - do ente processo - enquanto "ser" que pertence a um novo mundo não mais abarcado pelas certezas e infalibilidades modernas. Ressalta-se:

[...] só existe jurisdição enquanto há incerteza para as partes a respeito do conteúdo da futura sentença que haverá de dizer qual delas merece a proteção estatal por ser titular do direito protegido pela ordem jurídica [....]. Perante o processo, não pode haver nada evidente e indiscutível, uma vez que a previsibilidade absoluta e matemática do futuro resultado contido na sentença eliminaria, por si só, o próprio julgamento. Se a possibilidade de decisões antagônicas desaparecesse, o próprio fenômeno jurisdicional estaria eliminado. ${ }^{37}$ 
Neste rumo, a jurisdição não mais jurisdiciona somente o que está posto, não mais busca verdades eternas e, inatingíveis, não mais assenta-se na solidez da "segurança jurídica". Mas sim, jurisdiciona direitos difusos devendo resolver conflitos transindividuais surgidos desordenadamente e, muitas vezes, acontecendo em esfera global.

Desta forma, o processo acontece no tempo e, o tempo revela-se como horizonte do $\operatorname{ser}^{38}$, assim, a partir de uma nova visão temporal do processo será desvelado o "ser" processual enquanto ser hermenêutico por excelência, sendo a tutela jurisdicional (re)conduzida ao mundo da hermenêutica. ${ }^{39}$ Já que:

\begin{abstract}
Os conceitos jurídicos são, basicamente, hermenêuticos. A função hermenêutica, de que o direito processual nunca poderá prescindir, joganos na permanente antinomia, a que se refere Karl Engisch, entre a "abstração" jurídica inerente à norma, e a "totalidade concreta do caso. $\mathrm{O}$ sentido não está, univocamente, no texto. O sentido será dado, necessariamente, pelo intérprete. Não há um sentido a priori , independente do respectivo contexto em que ele se insere. Depois de estabelecer a "verdade" dos fatos, o que já constitui uma tarefa laboriosa e sempre discutível, quem tenha a tarefa de interpretar (aplicar) o direito, terá de encontrar o "significado" do "fato" - e tal processo, se dará pela hermenêutica - palavras minhas. ${ }^{40}$
\end{abstract}

Assim, do mesmo modo que é no tempo que se dá toda a compreensão do ser, no tempo dar-se-á a compreensão dos fatos enquanto pertencentes ao mundo do ser do processo, pois serão os fatos jogados na temporalidade ${ }^{41}$ a partir da qual serão pré-compreendidos e re-compreendidos, (re)significando no futuro as projeções presentes sobre o que foram no passado. ${ }^{42}$ Logo, o caminho da relação entre ser e tempo será refeito desobjetificando as estruturas jurídico-filosóficas da modernidade e trazendo a baila a inter-relação ser e tempo/tempo e ser. Neste passo:

\begin{abstract}
A viravolta que procurava dizer o ser, o que significa dizer o tempo vinculado com o ser, é o pensamento subterrâneo que perpassa quase quarenta anos do pensamento de Heidegger. Nesse longo período a mesma pergunta pelo sentido do ser continua como tema central de todos os trabalhos de Heidegger. A história da filosofia sempre revela que o ser nela ficou impensado, esquecido, confundido com os entes, e manifesta que o tempo vem, constantemente, ligado ao ser, sem que se problematize a relação entre ser e tempo. ${ }^{43}$
\end{abstract}

Nesta senda tendo-se que o processo não decorre em tempo real, esta recriação do tempo enquanto tempo processual vai se dar no círculo hermenêutico estando o mundo processual jogado na vida ${ }^{44}$, bem como, os fatos da vida jogados no processo e, a compreensão - sobre tais fatos - dando-se no horizonte temporal do ser - ser do "ser aí" explicitado na temporalidade ${ }^{45}$. Com efeito: 
do intérprete. Essa circunstância é muito peculiar, pois o ser vislumbra na temporalidade a sua condição de possibilidade de compreensão, ou seja, " o ser é entendido e apreendido a partir do tempo. E é por isso que Heidegger menciona que ser é tempo. ${ }^{46}$

Neste passo, o tempo - a temporalidade heideggeriana - é condição de possibilidade para o existir do ser enquanto "ser do mundo" e, por certo, para o existir do processo enquanto ser, ficando assim evidente a indissociável relação tempo-processo-ser ${ }^{47}$. Sendo que peculiarmente, o processo unifica os espaços temporais $^{48}$, pois bebe na fonte das memórias do passado, para acontecer no presente e, refletir-se no/em futuro, assim, percorrendo um fluxo temporal próprio e tridimensional apropriando-se das três dimensões temporais de uma só vez.

\footnotetext{
Desse modo, integrado nessas marcas rituais do tempo, o processo desenrola-se de uma assentada: representa-se até ao fim. Durante o período em que se desenvolve, apresenta avanços e recuos, peripécias, uma alternância de esperança e de pessimismo e, quando o fim se aproxima, a tensão. O processo é uma revolução completa. É por isso que se pode afirmar que a temporalidade processual não encontra possibilidade de reprodução. ${ }^{49}$
}

Logo, é a partir da compreensão circular hermenêutica que ganhará cor a jurisdição enquanto modus interpretativo-compreensivo assegurando o acontecer do Estado Democrático de Direito enquanto condição de possibilidade para o acontecer dela - jurisdição - enquanto jurisdição constitucional.

Desta forma, estando o processo inserido no mundo será a partir dele processo - que, abriram-se as portas para a compreensão constitucional do Direito e, sobremodo, para o desvelar da Constituição enquanto ser-no-mundo, passando a estar toda a compreensão/interpretação jurídica abarcada pelo "ser" constitucional.

\section{CONCLUSÃO}

Assim, adentra-se a pós-modernidade, caracterizada por um mundo de relações globais em que os sujeitos sociais, estão cada vez mais expostos às dúvidas e riscos da sociedade complexa e selvagem em que se vive.

Neste caminho, a sociedade contemporânea é uma constante produtora de incertezas, jogando todos ao caos e à complexidade das relações sociais de massa, onde o individuo está inserido em determinado grupo, o que, leva á conflitos transindividuais de direitos. Esta nova roupagem do social exige uma nova postura institucional por parte do Estado, e, por óbvio, não fica alheio a tais modificações o Direito.

Desta forma, não mais se coaduna com o atual momento histórico um Direito processual e, sobremodo, uma jurisdição calcada na produção de verdades absolutas atingidas através de certezas avaliadas com tal pelo julgador. No atual contexto, esta sim o processo, abarcado pelas incertezas dos fatos sociais, que deverão ao invés de produzir verdades, possibilitar ao magistrado a concretização 
de direitos. Direitos estes, albergados constitucionalmente e, que, são condição de possibilidade para o acontecer do Estado Democrático de Direito no Brasil.

\title{
LAW AND SCIENCE: DETERMINISM/POSITIVISM VERSUS INDETERMINISM/NEOCONTITUTIONALISM. COMMENTS ON THE TIME AND PROCESS
}

\begin{abstract}
This article discusses the relationship between Time and Law, especially in regard to the procedural time. The discussion focuses on the necessary (re) appropriate time in / time of the social process, making possible the effective protection of the rights guaranteed by the Bill of Rights. To this end, he believes it necessary to re-enter the process - the jurisdiction - in-world life, and eminently historical time, which will be made by philosophical hermeneutics.
\end{abstract}

Keiwords: Bill of Rights. Hermeneutics. Process. Time.

\section{NOTAS}

1 Bacharel em Direito pelo Centro Universitário Franciscano - UNIFRA, Santa Maria, RS, Brasil. Email: ferdhoffa@yahoo.com.br. Endereço: Centro Universitário Franciscano, Rua dos Andradas, 1614, CEP 97010-032 - Santa Maria-RS, Brasil.

2 Especializanda em Direito Público pela Escola Superior da Magistratura Federal (ESMAFE) e em Educação Ambiental pela Universidade Federal de Santa Maria (UFSM); Bacharel em Direito pelo Centro Universitário Franciscano. Advogada. Santa Maria - RS. E-mail: laranunes7@hotmail.com. Endereço: Centro Universitário Franciscano, Rua dos Andradas, 1614, CEP 97010-032 - Santa Maria-RS, Brasil.

3 Doutora em Direito Público pela Universidade do Vale do Rio dos Sinos (UNISINOS), com período de pesquisa na Universidade de Sevilha; Mestre em Direito Público pela Universidade de Santa Cruz do Sul (UNISC); Graduada em Direito pela Universidade Federal de Santa Maria (UFSM); Professora de Direito Constitucional e Direitos Humanos da Faculdade de Direito de Santa Maria (FADISMA); Professora de Direito Internacional e do Programa de Mestrado em Desenvolvimento da Universidade Regional do Noroeste do Estado do Rio Grande do Sul (UNIJUí); Advogada. Email: valribas@terra.com.br. Endereço: Faculdade de Direito de Santa Maria - Rua Duque de Caxias, 2319 - Nossa Senhora Medianeira - Santa Maria-RS, Brasil. D'MARAL, Marcio Tavares. Sobre O Tempo: considerações intempestivas. In. DOCTORS, Marcio (Org). Tempo dos Tempos. Rio de Janeiro: Jorge Zahar, 2003, p. 15.

5 KLEIN, Étienne. O Tempo. Lisboa: Instituto Piaget, 1995, p. 25.

6 MORETTO, Rodrigo. Crítica Interdisciplinar da Pena de Prisão: controle do espaço na sociedade do tempo. Rio de Janeiro: Lumen Júris, 2005, p. 4

7 KLEIN, Étienne. O Tempo. Lisboa: Instituto Piaget, 1995, p. 27.

8 MORETTO, Rodrigo. Crítica Interdisciplinar da Pena de Prisão: controle do espaço na sociedade do tempo. Rio de Janeiro: Lumen Júris, 2005, p. 13

9 OLIVEIRA, Luiz Alberto. Imagens do Tempo. In: DOCTORS, Marcio (Org). Tempo dos Tempos. Rio de Janeiro: Jorge Zahar, 2003, p. 57.

10 PRIGOGINE, llya. As Leis do Caos. São Paulo: UNESP, 2002, p. 11-12.

11 PRIGOGINE, Ilya. O Fim das Certezas: tempo, caos e as leis da natureza. São Paulo: UNESP, 1996, p. 12.

12 PRIGOGINE, Ilya. O Fim das Certezas: tempo, caos e as leis da natureza. São Paulo: UNESP, 1996, p. 12-13. 
PRIGOGINE, llya. O Nascimento do Tempo. Lisboa: Edições 70, 2008, p. 58.

OST, François. O Tempo do Direito. Porto Alegre: Instituto Piaget, 1999, p. 30.

BARZOTTO, Luis Fernando. O Positivismo Jurídico Contemporâneo: uma introdução a Kelsen, Ross e Hart. Porto Alegre: Livraria do Advogado, 2007, p. 25.

ROCHA, Leonel Severo. Tempo e Constituição. Revista Direitos Culturais, Santo Ângelo, v.1 - n. 1, dez. 2006.2 Disponível em: <http://srvapp2s.urisan.tche.br/seer/index.php/direitosculturais/article/view/122/103>. Acesso em: 17 mar. 2010, p 178.

17 ROCHA, Leonel Severo. Lex Mercatoria e Governança: a policontextualidade entre direito e estado. Revista Direitos Culturais, Santo Ângelo, v. 1 - n. 2, jun. 2007 Disponível em: <http://srvapp2s.urisan.tche.br/seer/index.php/direitosculturais/article/view/109/89>. Acesso em: 17 mar. 2010, p. 74-76.

18 ROCHA, Leonel Severo. Epistemologia Jurídica e Democracia. São Leopoldo: UNISINOS, 2003, p. 197.

19 SPENGLER, Fabiana Marion. Tempo, Direito e Constituição: reflexos na prestação jurisdicional do Estado. Porto Alegre: Livraria do Advogado, 2008, p. 29.

20 LUCAS, Doglas Cesar. A Crise Funcional do Estado e o cenário da jurisdição desafiada. In: MORAIS, José Luis Bolzan de (Org). O Estado e Suas Crises. Porto Alegre: Livraria do Advogado, 2005, p. 178.

21 SILVA, Ovídio A. Baptista da. Processo e Ideologia: o paradigma racionalista. Rio de Janeiro: Forense, 2006, p. 1.

22 NEVES, Antonio Castanheira, apud, SILVA, Ovídio A. Baptista da. Verdade e Significado. Disponível em: <http//www.baptistadasilva.com.br/artigos006.htm>. Acesso em: 18 set. 2008. sp. SILVA, Ovídio A. Baptista da. Verdade e Significado. Disponível em: $<$ http//www.baptistadasilva.com.br/artigos006.htm>. Acesso em: 18 set. 2008. sp.

24 ENGELMANN, Wilson. A Crise Constitucional: a linguagem e os direitos humanos como condição de possibilidade para preservar o papel da Constituição no mundo globalizado. In: MORAIS, José Luis Bolzan de (Org). O Estado e Suas Crises. Porto Alegre: Livraria do Advogado, 2005, p. 236. Embora o autor refira-se diretamente ao Direito Processual Penal, também é o Processo Civil relacionado á fatos que ocorrem no mundo e, logo, no tempo. Pois o Processo como um todo, ocorre no tempo, ocorre onde a vida flui, onde está o mundo, onde o acontecer social materializase instituindo o acontecer jurídico-político.

THUMS, Gilberto. Sistemas Processuais Penais: tempo, tecnologia, dromologia, garantismo. Rio de Janeiro: Lumen Juris, 2006, p. 1.

27 MORAIS, José Luis Bolzan de; SALDANHA, Jânia Maria Lopes; ESPÍNDOLA, Ângela Araújo da Silveira. Jurisdição Constitucional e Participação Cidadã: por um processo formal e substancialmente vinculado aos princípios político-constitucionais. In: OLIVEIRA, Marcelo Andrade Cattoni de e MACHADO, Felipe Daniel Amorim. (Org). Constituição e Processo: A colaboração do processo ao constitucionalismo democrático brasileiro. Belo Horizonte: Del Rey, 2009, p.124. STRECK, Lenio Luiz. Verdade e Consenso: Constituição, Hermenêutica e Teorias Discursivas. Rio de Janeiro: Lúmen Júris, 2006, p. 115-116. OLIVEIRA, Luiz Alberto. Imagens do Tempo. In: DOCTORS, Marcio (Org). Tempo dos Tempos. Rio de Janeiro: Jorge Zahar, 2003, p. 65.

31 JAGUARIBE, Helio. Tempo e História. In: DOCTORS, Marcio (Org). Tempo dos Tempos. Rio de Janeiro: Jorge Zahar, 2003, p. 164. ANTOUN, Henrique. Nietzsche: o tempo e a têmpera. In: DOCTORS, Marcio (Org). Tempo dos Tempos. Rio de Janeiro: Jorge Zahar, 2003, p. 110.

33 LOPES JÚNIOR, Aury. (Des)Velando o Risco e o Tempo no Processo Penal. In: GAUER, Ruth Maria Chittó. A Qualidade do Tempo: para além das aparências históricas. Rio de Janeiro: Lumen Juris, 2004, p. 154 HOMMERDING, Adalberto Narciso. Fundamentos Para Uma Compreensão Hermenêutica do Processo Civil. Porto Alegre: Livraria do Advogado, 2007, p. 141-142.

LOPES JÚNIOR, Aury. (Des)Velando o Risco e o Tempo no Processo Penal. In: GAUER, Ruth Maria Chittó. A Qualidade do Tempo: para além das aparências históricas. Rio de Janeiro: Lumen Juris, 2004, p. 159

37 SILVA, Ovídio A. Baptista da. Curso de Processo Civil I: Processo de Conhecimento. Rio de Janeiro: Forense, 2006, p. 7. 
Em Heidegger não há que procurar-se a origem do tempo em algo dado plenipotenciariamente, mas sim, em nós mesmos enquanto seres jogados na temporalidade. Assim pergunta-se heideggerianamente, quem é o tempo? Responde-se, o tempo é ser, enquanto "se-aí" envolto à temporalidade, vislumbra-se assim, a íntima relação entre o ser humano e o tempo, donde o ser não existe no tempo, pois já é temporal, já é tempo. DASTUR, Françoise. Heidegger e a Questão do Tempo. Lisboa: Instituto Piaget, 1997, p. 29.

39 ENGELMANN, Wilson. Direito Natural, Ética e Hermenêutica. Porto Alegre: Livraria do Advogado, 2007, p. 210.

40 SILVA, Ovídio A. Baptista da. Verdade e Significado. Disponível em: $<$ http//www.baptistadasilva.com.br/artigos006.htm>. Acesso em: 18 set. 2008. sp.

41 Em Heidegger divide-se o espectro temporal em duas "dimensões" por assim dizer: o conceito vulgar de tempo e a temporalidade. Para Heidegger o conceito vulgar de tempo, enquanto simplesmente passado, presente e, futuro ou ainda, enquanto tempo subjetivo e objetivo, são impressões a respeito do fenômeno temporal nascidas de uma compreensão imprópria do que seria o tempo. Para tanto, estaria na temporalidade a emanação temporal enquanto "ser-em-si", enquanto condição de possibilidade para compreender o ser do "ser-em-si". A temporalidade é o horizonte de acontecimento/desvelamento do ser e, logo, é também, onde se dá a compreensão do "ser" enquanto "ser" de algo - enquanto ser de um ente. HEIDEGGER, Martin. Ser e Tempo. Rio de Janeiro: Vozes, 2006, p. 383 e ss. ENGELMANN, Wilson. Direito Natural, Ética e Hermenêutica. Porto Alegre: Livraria do Advogado, 2007, p. 225.

43 STEIN, Ernildo. Compreensão e Finitude: estrutura e movimento da interrogação heideggeriana. Ijuí: UNIJUI, 2001, p. 338. SPENGLER, Fabiana Marion. Tempo, Direito e Constituição: reflexos na prestação jurisdicional do Estado. Porto Alegre: Livraria do Advogado, 2008, p. 44. STEIN, Ernildo. Compreensão e Finitude: estrutura e movimento da interrogação heideggeriana. ljuí: UNIJUI, 2001, p. 332. ENGELMANN, Wilson. Direito Natural, Ética e Hermenêutica. Porto Alegre: Livraria do Advogado, 2007, p. 227.

47 Só se pode falar do tempo, estando no tempo, "este é o único meio de falar temporalmente do tempo, em vez de o hipostasiar como um ser diferente de nós", ser é tempo e tempo é ser, assim, tempo e ser são e compreendem-se temporalmente. Assim, ser e tempo identificam-se mutuamente enquanto "seres" eminentemente temporais. DASTUR, Françoise. Heidegger e a Questão do Tempo. Lisboa: Instituto Piaget, 1997, p. 29. Com efeito: "Descoberto o tempo originário como ser do ser-aí dever-se-ia manifestar esse tempo como lugar da eclosão do ser, como o próprio ser. Um movimento linear da analítica existencial para o tempo ligado ao ser não seria possível. Seria necessário pensar o ser como tempo e, então, refazer a analítica existencial, a partir desse conceito de ser". STEIN, Ernildo. Compreensão e Finitude: estrutura e movimento da interrogação heideggeriana. Ijuí: UNIJUI, 2001, p. 337.

Neste ponto se mostra importante algumas considerações a respeito da relação presente, passado e futuro em Heidegger. Assim, o futuro é apresentado neste contexto como "porvir" significando uma constante antecipação de/do sentido do próprio ser revelando-se cotidianamente e, originando o mundo circundante ou seja, "o futuro é o próprio ser interpelado pela realidade". O passado mostra-se como "o vigor de ter sido", que mesmo consumado, ainda produz efeitos no tempo atual. Neste passo, o presente denomina-se "atualidade" "no sentido de deixar vir ao encontro do homem as possibilidades de ação onde se encontra inserido". Logo, o futuro, o vigor de ter sido - passado - e o presente conjugam-se a partir de um horizonte de sentido que alinhas estas três dimensões temporais harmonizando-as na sua inter-relação com o ser do ente humano - ser-humano. Dessa forma, é que não se compreende a partir de um ente dado atemporalmente, pois este compreender está vinculado ao sentido projetado pela/na temporalidade. ENGELMANN, Wilson. Direito Natural, Ética e Hermenêutica. Porto Alegre: Livraria do Advogado, 2007, p. 227-228.

49 SPENGLER, Fabiana Marion; SPENGLER NETO, Theobaldo. O “Tempo da Jurisdição" e o "Tempo da Mediação": as verdade(s) conflitiva(s) e o seu tratamento. Revista do Direito, Santa Cruz do Sul, no 30, jul-dez. 2008. Disponível em: <http://online.unisc.br/seer/index.php/direito/article/viewFile/681/470>. Acesso em: 13 mai. 2010, p. 10. 


\section{REFERÊNCIAS}

ANTOUN, Henrique. Nietzsche: o tempo e a têmpera. In: DOCTORS, Marcio (Org). Tempo dos Tempos. Rio de Janeiro: Jorge Zahar, 2003.

BARZOTTO, Luis Fernando. O Positivismo Jurídico Contemporâneo: uma introdução a Kelsen, Ross e Hart. Porto Alegre: Livraria do Advogado, 2007.

BAUMAN, Zygmunt. Modernidade Líquída. Rio de Janeiro: Jorge Zahar, 2001.

DASTUR, Françoise. Heidegger e a Questão do Tempo. Lisboa: Instituto Piaget, 1997.

D'MARAL, Marcio Tavares. Sobre O Tempo: considerações intempestivas. In. DOCTORS, Marcio (Org). Tempo dos Tempos. Rio de Janeiro: Jorge Zahar, 2003.

ENGELMANN, Wilson. Direito Natural, Ética e Hermenêutica. Porto Alegre: Livraria do Advogado, 2007.

ENGELMANN, Wilson. A Crise Constitucional: a linguagem e os direitos humanos como condição de possibilidade para preservar o papel da Constituição no mundo globalizado. In: MORAIS, José Luis Bolzan de (Org). O Estado e Suas Crises. Porto Alegre: Livraria do Advogado, 2005.

HEIDEGGER, Martin. Ser e Tempo. Rio de Janeiro: Vozes, 2006.

HOMMERDING, Adalberto Narciso. Fundamentos Para Uma Compreensão Hermenêutica do Processo Civil. Porto Alegre: Livraria do Advogado, 2007.

JAGUARIBE, Helio. Tempo e História. In: DOCTORS, Marcio (Org). Tempo dos Tempos. Rio de Janeiro: Jorge Zahar, 2003.

KLEIN, Étienne. O Tempo. Lisboa: Instituto Piaget, 1995.

LOPES JÚNIOR, Aury. (Des)Velando o Risco e o Tempo no Processo Penal. In: GAUER, Ruth Maria Chittó. A Qualidade do Tempo: para além das aparências históricas. Rio de Janeiro: Lumen Juris, 2004.

LUCAS, Doglas César. A Crise Funcional do Estado e o Cenário da Jurisdição Desafiada. In: MORAIS, José Luis Bolzan de (Org). O Estado e suas Crises. Porto Alegre. Livraria do Advogado, 2005.

MORAIS, José Luis Bolzan de; SALDANHA, Jânia Maria Lopes; ESPÍNDOLA, Ângela Araújo da Silveira. Jurisdição Constitucional e Participação Cidadã: por um processo formal e substancialmente vinculado aos princípios político-constitucionais. In: OLIVEIRA, Marcelo Andrade Cattoni de e MACHADO, Felipe Daniel Amorim. 
(Org). Constituição e Processo: A colaboração do processo ao constitucionalismo democrático brasileiro. Belo Horizonte: Del Rey, 2009.

MORETTO, Rodrigo. Crítica Interdisciplinar da Pena de Prisão: controle do espaço na sociedade do tempo. Rio de Janeiro: Lumen Júris, 2005.

OLIVEIRA, Luiz Alberto. Imagens do Tempo. In: DOCTORS, Marcio (Org). Tempo dos Tempos. Rio de Janeiro: Jorge Zahar, 2003.

OST, François. O Tempo do Direito. Porto Alegre: Instituto Piaget, 1999.

PRIGOGINE, llya. As Leis do Caos. São Paulo: UNESP, 2002.

PRIGOGINE, llya. O Fim das Certezas: tempo, caos e as leis da natureza. São Paulo: UNESP, 1996.

PRIGOGINE, llya. O Nascimento do Tempo. Lisboa: Edições 70, 2008.

ROCHA, Leonel Severo. Epistemologia Jurídica e Democracia. São Leopoldo: UNISINOS, 2003.

ROCHA, Leonel Severo. Lex Mercatoria e Governança: a policontextualidade entre direito e estado. Revista Direitos Culturais, Santo Ângelo, v. 1 - n. 2, jun. 2007 Disponível em: <http://srvapp2s.urisan.tche.br/seer/index.php/direitosculturais/article/view/109/89>. Acesso em: 17 mar. 2010.

ROCHA, Leonel Severo. Tempo e Constituição. Revista Direitos Culturais, Santo Ângelo, v.1 - n. 1, dez. 2006. Disponível em: $<$ http://srvapp2s.urisan.tche.br/seer/index.php/direitosculturais/article/view/122/103>. Acesso em: 17 mar. 2010.

SILVA, Ovídio A. Baptista da. Processo e Ideologia: o paradigma racionalista. Rio de Janeiro: Forense, 2006.

SILVA, Ovídio A. Baptista da. Curso de Processo Civil I: Processo de Conhecimento. Rio de Janeiro: Forense, 2006.

SILVA, Ovídio A. Baptista da. Verdade e Significado. Disponível em: $<$ http//www.baptistadasilva.com.br/artigos006.htm>. Acesso em: 18 set. 2008.

SPENGLER, Fabiana Marion. Tempo, Direito e Constituição: reflexos na prestação jurisdicional do Estado. Porto Alegre: Livraria do Advogado, 2008.

SPENGLER, Fabiana Marion; SPENGLER NETO, Theobaldo. O "Tempo da Jurisdição" e o "Tempo da Mediação": as verdade(s) conflitiva(s) e o seu tratamento. Revista do Direito, Santa Cruz do Sul, no 30, jul-dez. 2008. Disponível em: $<$ http://online.unisc.br/seer/index.php/direito/article/viewFile/681/470>. Acesso em: 13 mai. 2010. 
STEIN, Ernildo. Compreensão e Finitude: estrutura e movimento da interrogação heideggeriana. Ijuí: UNIJUI, 2001.

STRECK, Lenio Luiz. Verdade e Consenso: constituição, hermenêutica e teorias discursivas. Rio de Janeiro: Lumen Juris, 2006.

THUMS, Gilberto. Sistemas Processuais Penais: tempo, tecnologia, dromologia, garantismo. Rio de Janeiro: Lumen Juris, 2006.

Recebido para publicação: 18/08/2010

Aceito para publicação: 23/12/2010 